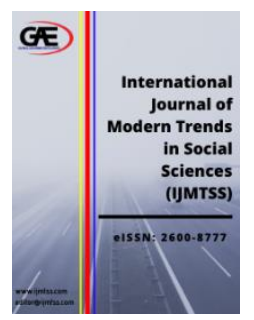

\author{
INTERNATIONAL JOURNAL OF \\ MODERN TRENDS IN \\ SOCIAL SCIENCES \\ (IJMTSS) \\ www.ijmtss.com
}

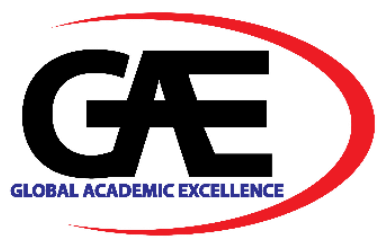

\title{
THE INFLUENCE OF GENDER DIFFERENCES ON INSTAGRAM USAGE AMONG HIGHER INSTITUTION STUDENTS
}

\author{
Azureen Abd Aziz ${ }^{1 *}$, Afiqah Abd Aziz
}

1 Centre Of Liberal Arts And Language, Inti International University, Malaysia

Email: azureen.abdaziz@newinti.edu.my

2 Centre of Foundation Studies, Universiti Teknologi MARA, Universiti Teknologi MARA, Cawangan Selangor, Kampus Dengkil, 43800 Dengkil, Selangor, Malaysia

Email: afiqahaziz@uitm.edu.my

* Corresponding Author

\section{Article Info:}

Article history:

Received date:08.10.2020

Revised date: 20.10 .2020

Accepted date: 22.11 .2020

Published date: 03.12.2020

\section{To cite this document:}

Abd Aziz, A., \& Abd Aziz, A. (2020). The Influence of Gender Differences on Instagram Usage among Higher Institution Students. International Journal of Modern Trends in Social Sciences, 3 (14), 78-83.

DOI: $10.35631 /$ IJMTSS.314007

This work is licensed under CC BY 4.0

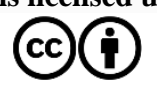

\begin{abstract}
:
Instagram, the photo, and the video-sharing social medium are rapidly gaining popularity. Malaysia presents an excellent case for exploring the influence of culture on Instagram use. Like other developing countries, the traditional culture of Malaysia greatly affects the attitudes and behaviors of its people. It is interesting to examine the influence of gender on Instagram use activities. In Malaysia, the culture, besides security reasons, inhabits females from disclosing contact information. The central theme of this research paper is to understand gender differences in Instagram use by students in higher education students. This study uses the quantitative method where it involves 200 university students as the participants. The sample was selected among the students who take general studies in order to have a concrete result. This study confirms that males are more likely than females to post their personal pictures on Instagram, more likely to disclose their personal information, and more likely to have public accounts, unlike females who are more likely to have private accounts than males.
\end{abstract}

Keywords:

Social Media, Gender Differences, Cultural Differences, Media And Culture, Usability, Instagram

\section{Introduction}

Instagram, the photo and video-sharing social medium, is rapidly gaining popularity and preference with more than 200 million users and $13 \%$ of the total users of social media placing it fourth in rank after Facebook, Twitter and Pinterest. It is a social media application that 


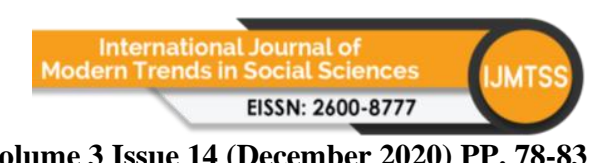

Volume 3 Issue 14 (December 2020) PP. 78-83

DOI 10.35631/IJMTSS.314007

allows people to share with others their daily life activities, lifestyles, habits and interests in pictures and videos. Instagram is easy to operate, and it only requires downloading, choosing a username and password, and finally posting pictures that others see. People can either upload posts taken instantly or stored ones from their mobile phone gallery.

A background survey of Instagram users in Taiwan revealed that female users constitute the majority and are also more active. Furthermore, most users have a college education or higher (Kim \& Han 2014). In Taiwan, significantly more individuals from junior high school students at the age of 12 to fresh university graduates under the age of 24 visit Instagram than individuals from other age group. Moreover, 71\% of young people between the ages of 18 and 24 are Instagram users. This shows that Instagram is extremely popular among young people in Taiwan. On Instagram, users can currently share posts in the form of images, videos, carousels, and stories (Marcus, 2015). In addition to user posts, an increasing number of commercial brands aimed at young individuals are placing ads on Instagram via Facebook. Pricing is adjusted in real-time, ads are displayed to audiences, and services are offered in real-time. The image, video, carousel, and stories formats are also available for Instagram ads. Stories ads can be $2.5 \mathrm{~s}$ to $60 \mathrm{~s}$ long, whereas carousel ads comprise three to five images that can be scrolled left and right, which adds to the fun (Sheldon \& Bryan, 2016)

Like other social networks, Instagram is fabricated on having followers like family, friends or strangers who follow the updates of Instagrammers' life via posted pictures and videos. Created profiles include personal information and a picture to identify the account. People either create public, directly accessed, accounts or private ones that require seeking permission from the Instagrammer before viewing the posts. Once following Instagrammers, followers can view the pictures and videos' timelines. People viewing the posts can interact with what they see by pressing the "Like" button or provide comments to express their opinions on the posts.

Malaysia presents an excellent case for exploring the influence of culture on Instagram use. Like other developing countries, the traditional culture of Malaysia greatly affects the attitudes and behaviors of its people. It is interesting to examine the influence of gender on Instagram use activities. In Malaysia, females have been subjugated by a cultural conservatism.

\section{Literature Review}

Wherever Females compose the majority users of many Social Networking Sites (SNS), Facebook, MySpace, Twitter, Bebo, Flickr and Pinterest. Conversely, males make up the majority of Google's users (71\%), Digg, YouTube and LinkedIn (Lenhart.M 2009). These surveys confirm that the nature, functions and design of social media determines their users and effects. Females prefer Facebook, Twitter, and Pinterest because they are interpersonal and discussion-oriented while males favor Google, Digg, YouTube and LinkedIn because they are information and content-oriented (Guadagno and Cialdini, 2007). We also argue that females prefer social media more than males because these media are primarily social in their nature and this nature is similar to the social makeup of females.

Instagram use by males and females will not eschew from those uses of other social media. Females use it to socialize and provide opinion while males use it to collect information and pass time. Both will use it to present their daily life to others, however, the culture and traditions of Malaysia may mediate such use. Females will be more reserved about presenting themselves to others in personal pictures because the "social attitudes have remained relatively constant" (Nydell.M, 2006) in the conservative culture. 


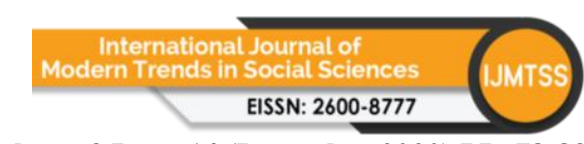

Volume 3 Issue 14 (December 2020) PP. 78-83

DOI 10.35631/IJMTSS.314007

In addition, among the higher institutions students', family honor, which has roots in the sexual conducts of females, is an important value that has to remain unsoiled. If not bounded by marriage, such conducts bring shame to family and "blacken its face". It is difficult to erase or restore a dishonor. Thus, many families will think that posting personal pictures of females show them as having playful and unrestrained character that seeks relations with males. This is to avoid giving "rise to false impressions or unfounded gossip". (Patai, R, 2007). Therefore, even if females post personal photos, they have to appear sober and modest in them and not reveal much of their bodies. Also, females who have public accounts will avoid posting their personal pictures in favor of pictures of materials they own or places they go.

\section{Privacy Settings}

More females believe that there is risk online. They report more about privacy concerns (Hoy.M and Milne.G, 2010) and are more likely to read privacy statements (Milne. R, George, and. Culnan.M 2004). This interest in the online privacy issues by females is perhaps because they are more likely to be victims of online abuse. According to the Working to Hold Online Abuse Organization, 73\% of the 2500 online harassment and stalking cases from 2000 to 2008 are for females. Hence, in order to maintain their privacy, they create private accounts, (Fogel.J and Nehmad.E, 2009) support privacy policies and provide false information (Sheehan and Doherty, 2001)

Females' students will probably be more likely to create private accounts on Instagram due to safety and more importantly cultural reasons. Many fathers, brothers and husbands will reject that females have stranger male followers because it communicates a negative impression or create bad reputation about the females. Conversely, having a private account may communicate that a female is moral and well-mannered. More likely, males will have public accounts and followers from the opposite sex because "The misbehavior by women is believed to do more damage to family honor than the misbehavior of men" On the other hand, males can go out with anyone and come back at any time while females are restricted. Thus, they will limit their Instagram's relationships only to family and friends. Even in the United States, 52\% of females say that their social media profiles are set private so that only friends view them.

\section{Information Disclosure}

Females are extroverted and reveal more information about themselves on Facebook. This personal information includes their relationships, preferences, jobs, and religious affiliations (Kolek and Saunders, 2008) However, more often than females, males provide their contact information such as telephone numbers, emails and home addresses on their social network profile accounts. Moreover, female students feel more worried about providing such information compared to male. About $20 \%$ of them say they will share their location details in comparison to $65 \%$ of males. Also, $55 \%$ of males will share their email contact while only $42 \%$ of females will do so.

In most of the higher institutions in Malaysia, the culture, besides security reasons, inhabits females from disclosing contact information. This culture assumes that "the inherent personalities between men and women are vastly different". Females who display contacts will be perceived as flirty and frivolous. Displaying contact information will reveal males flirty and wanting to contact females too, but the culture is less critical to males. It gives them more freedom in behaving and movement than females. It also forbids interaction between males and females who are strange to each other. Generally, it is indecent if a male and female stay 
behind closed doors or go out on a date. That is why there is a separation between males and females in social gatherings, and higher institutions (Examiner, 2012)

\section{A Cross-Cultural View of Gender Differences}

A model for understanding cross-cultural communication is provided by (Gumperz, 1982). That such an approach can be applied to conversations between women and men is supported by ethnographic research on language socialization by sociologists and anthropologists, especially the extensive work of Goodwin (see her paper in this issue) and the overview provided by (Maltz and Borker, 1982). Only a brief summary can be provided here. Reviewing the work of Goodwin and others, Maltz and Borker explain that males and females learn their styles of talking in sex-separate peer groups. 2 In this sense, they grow up in different cultural environments, so they develop different habits for signaling their intentions and understandings. Because they learn to have conversations in same-sex peer interaction, women and men devel. op different boons for establishing and displaying conversational involvement. These "cultural" differences account for the differing patterns observed among girls and boys and women and men, as well as for mutual negative evaluations that often result from crossgender interactions (Tannen, 1990)

\section{Hypothesis}

The central theme of this research paper is to understand the influence of culture on Instagram use by Malaysian higher education students. The following research questions are posited: Accordingly, this study tries to answer and confirm three hypotheses:

Hypothesis 1: Males are more likely to post their personal pictures on Instagram than females. Hypothesis 2: Females are more likely to have private Instagram accounts than males.

Hypothesis 3: Males are more likely to reveal their personal information on their profile accounts than females.

\section{Methods}

The sample of this study includes university students in Malaysia. This segment is chosen because it uses Instagram more often that other age groups. About 200 university students participated in a questionnaire that took about 10 minutes to fill out. It was distributed to students who were enrolled in general education courses to guarantee a sample representing diverse body of students from different fields. The questionnaire was in English and it took about 15 minutes to fill out. Subjects were told that there information will be confidential.

\section{Results}

This study seeks to confirm its three hypotheses. In order to confirm them, independent t-test procedures were used to find out the differences between males and females. The first hypothesis stated, males are more likely to post their personal pictures on Instagram than females. The t-test revealed that males $(\mathrm{M}=1.82 ; \mathrm{SD}=.38)$, more than females $(\mathrm{M}=1.49 ; \mathrm{SD}$ $=.50)$, posted personal pictures on Instagram $(\mathrm{t}(522)=8.00, \mathrm{p}=.001)$. This finding confirms the first hypothesis.

The second hypothesis stated that Females are more likely to have private Instagram accounts than males. The t-test statistical procedure confirmed this hypothesis. Males $(\mathrm{M}=1.21 ; \mathrm{SD}=$ $.41)$ are more likely than females $(M=1.10 ; S D=.30)$ to have public accounts $(t(520)=3.54$, $\mathrm{p}=.001)$. 
The last hypothesis which stated that Males are more likely to reveal their personal information on their profile accounts than females. The t-test revealed that More frequently than females $(\mathrm{M}=2.92 ; \mathrm{SD}=1.77)$, males $(\mathrm{M}=3.68 ; \mathrm{SD}=2.01)$ disclose their personal information $(\mathrm{t}$ $(527)=4.49, \mathrm{p}=.001)$. The third hypothesis is confirmed. Table I bellow shows types of information, each gender disclosed with percentage.

\begin{tabular}{|l|l|l|l|l|l|l|}
\hline \multirow{2}{*}{$\begin{array}{l}\text { Information } \\
\text { Disclosed }\end{array}$} & \multicolumn{7}{|c|}{ Males } & Rank & $\%$ & Freq. & Rank & $\%$ \\
\cline { 2 - 7 } Real Name & 152 & 1 & 78 & 206 & 1 & 59 \\
\hline $\begin{array}{l}\text { Personal } \\
\text { Pictures }\end{array}$ & 140 & 2 & 72 & 126 & 3 & 37 \\
\hline $\begin{array}{l}\text { Preferred } \\
\text { Saying }\end{array}$ & 77 & 3 & 40 & 175 & 2 & 51 \\
\hline $\begin{array}{l}\text { Age/ } \\
\text { Birthday }\end{array}$ & 57 & 5 & 29 & 101 & 4 & 29 \\
\hline $\begin{array}{l}\text { Major/School } \\
\text { Of Study }\end{array}$ & 57 & 5 & 29 & 92 & 5 & 27 \\
\hline Contacts & 47 & 6 & 24 & 42 & 9 & 12 \\
\hline $\begin{array}{l}\text { Interests And } \\
\text { Hobbies }\end{array}$ & 46 & 7 & 24 & 67 & 7 & 19 \\
\hline \multicolumn{1}{|c|}{ Gender } & 36 & 8 & 19 & 68 & 6 & 20 \\
\hline Nationality & 34 & 9 & 18 & 52 & 8 & 15 \\
\hline Job Title & 24 & 10 & 12 & 17 & 11 & 5 \\
\hline $\begin{array}{l}\text { Place Of } \\
\text { Living }\end{array}$ & 18 & 11 & 9 & 16 & 12 & 5 \\
\hline $\begin{array}{l}\text { Marital } \\
\text { Status }\end{array}$ & 18 & 12 & 9 & 22 & 12 & 6 \\
\hline
\end{tabular}

Table 1: Types of Information, Each Gender with \%

\section{Discussion and Conclusion}

This paper sought to find out the influence of culture on Instagram use between males and females. This study confirms that males are more likely than females to post their personal pictures on Instagram, more likely to disclose their personal information and more likely to have public accounts unlike females who are more likely to have private accounts than males. Such findings confirm what has been discussed in the literature review. Such culture has always preferred males over females and this is why males are more likely than females to post their personal pictures or disclose their personal information on Instagram. The image of a female is part of the image of the entire family or clan. Father, brothers and husbands probably will allow females to have Instagram accounts, but would probably not prefer that their sisters, wives and daughters to post their personal pictures especially if they have public accounts or disclose personal information. Such conduct might "blacken its face" of the family. "Guarding a woman's image is neither a personal nor a family choice; it is imposed by the culture".

This is also similar to having public accounts by females. Families are more likely to reject that their daughters to allow other stranger males to follow them. Having males followers may shows a female who is a playful. Such image is because "The misbehavior by women is believed to do more damage to family honor than the misbehavior of men". 
Future studies might compare between Malaysia and Western females on the use of Instagram. Using a cultural perspective might further highlight the influence on culture on the use of various social media. Future studies might also examine age as a factor influence usage of Instagram in issues related to privacy settings, disclosure, types of pictures posted, and level of involvements, etc.

\section{References}

Bernner, M. D. (2013). The demographics of social media users-2012. The Pew Research Internet Project.

D. Williams, M. C. (2009). Looking for gender (LFG): Gender roles and behaviors among online gamers. Journal of Communication , vol. 59, , 700-725.

Goudreau, J. (2010). What men and women are doing on Facebook. .

Gumpen, J. J. (1982). Discourse strategies. Cambridge University Press. .

K. B. Sheehan and C. Doherty. (2001). Re-weaving the web: Integrating print and online communication. Journal of Interactive Marketing, vol. 15, no. 2, , 47-59.

Kim, Y., \& Han, J. (2014). Why smartphone advertising attracts customers: A model of Web advertising, flow, andpersonalization. Comput. Hum. Behav. 256-269.

Lenhart, A. (February 20, 2009). Adults and social network websites," Pew Internet \& American Life Project.

Marcus, S. (2015). Picturing' ourselves into being: Assessing identity, sociality and visuality on Instagram. In Proceedings of the International Communication Association Conference, San Juan, Puerto Rico, .

Nehmad, J. F. (2009). Internet social network communities: Risk taking, trust and privacy concerns. Computers in Human Behavior, vol. 25, 153-160.

Saunders, E. A. (2008). Online disclosure: An empirical examination of undergraduate Facebook profiles. NASPA Journal, vol. 45, no. 1, 1-25.

Sheldon, P., \& Bryan, K. (2016). Instagram: Motives for its use and relationship to narcissism and contextual age. Comput. Hum. Behav, 89-97.

Shubin, E. (2012). Gender differences in social media usage.

Smith, A. (2014). The numbers: 85 interesting Instagram statistics. Digital Marketing Rambling.

Tannen, D. (1990). Gender Differences in Topical Coherence: Creating Involvement in Best Friends' Talk", Discourse processes 13. 73-90.

Ward, B. (2011). Even in virtual environments women shop and men build: A social. 